\title{
Variación fonológica de la /d/ intervocálica en el sociolecto alto de Sevilla*
}

Phonological Variation of Intervocalic /d/
in the High Sociolect in the City of Seville

RAFAEL JimÉNEZ FERNÁNDEZ

Didáctica de la Lengua y la Literatura

RECIBIDO: 19 DE OCTUBRE DE 2018 ACEPTADO: 21 DE ENERO DE 2019

Facultad de Ciencias de la Educación

Universidad de Cádiz

Avd. República Saharaui, s/n. Puerto Real (Cádiz), 11519

rafael.jimenezfernandez@uca.es

Orcid ID 0000-0001-8665-6788

Resumen: En este artículo se analiza el proceso de mantenimiento y elisión de la /d/ intervocálica en el español hablado en la ciudad de Sevilla. Para ello nos hemos basado en los materiales de sociolecto alto de PRESEEA-Sevilla, que se compone de 24 encuestas semidirigidas grabadas entre los años 2009 y 2015. Nuestro objetivo es analizar qué factores lingüísticos y extralingüísticos (sociales y estilísticos) inciden en la variación fonológica de la dental. Los resultados se han obtenido mediante un análisis estadístico de correlaciones bivariantes y de regresión que estudia la incidencia de las variables lingüísticas independientes en la conservación o elisión del sonido intervocálico. La investigación se completa con una descripción de los usos individuales de los hablantes en los entornos fónicos general y-ado.

Palabras clave: Sociolingüística. Variación fonológica. /d/ intervocálica. Sevilla. Sociolecto alto.
Abstract: This article analyzes the maintenance and elision of the intervocalic / $/$ / phoneme in the Spanish spoken in the city of Seville. For this purpose, the study is based on PRESEEA materials from the high sociolect of Seville's citizens, which is made of semi-structured surveys recollected between 2009 and 2015. The aim of this paper is to analyze what linguistic and extralinguistic (social and stylistic) factors influence the phonological variation of the dental. The results have been obtained from the application of statistic correlations and regression analyses in order to study the influence of independient linguistic variables in the conservation or elision of intervocalic sound. Our research is completed with the description of the individual uses of the speakers in the general phonetic context and the -ado phonetic context.

Keywords: Sociolinguistics. Phonological Variation. Intervocalic /d/ Phoneme. Seville. High Sociolect.

* Esta investigación se ha realizado con los materiales del Proyecto de Estudio Sociolingüístico del Español de España y América (PRESEEA) de Sevilla, recopilados por los miembros del grupo de investigación Sociolingüística Andaluza: Estudio Sociolinguiístico del Habla de Sevilla (HUM 141). Este trabajo se encuadra específicamente entre los objetivos del Proyecto Patrones Sociolinguiústicos del Español de Sevilla (PASOS-SE), Proyecto I+D Excelencia, convocatoria de 2015, financiado por el Ministerio de Economía y Competitividad de España (referencia FFI2015-68171-C5-3-P, MINECO/FEDER/UE). 


\section{INTRODUCCIÓN}

a pérdida de la /d/ intervocálica es un fenómeno antiguo bien conocido en la mayoría de las modalidades hispánicas. Comienza a omitirse desde fines del siglo XIV en las desinencias verbales acabadas en -des, se propaga a textos descuidados o muy vulgares del siglo XVI, como el quedao del Cancionero de Pedro del Pozo de 1547 o el calsaos americano de 1583, y se generaliza en la segunda mitad del siglo XVII. En 1701 el gramático francés Maunory atestigua en Madrid la desaparición de la sonora dental en participios trisílabos o tetrasílabos terminados en -ado y no en otros bisílabos ni en los sustantivos (Zamora 66; Lapesa 389). ${ }^{1}$

Actualmente, y tras el definitivo impulso de los estudios de sociolingüística urbana, el proceso de debilitamiento y pérdida de la /d/ intervocálica se ha convertido en foco de atención de numerosos investigadores interesados en el análisis de determinados hechos lingüísticos en su contexto social de producción. ${ }^{2}$ Es justo reconocer, en este sentido, los trabajos realizados en distintas comunidades de habla hispanoamericanas y españolas por quienes forman parte del "Proyecto para el Estudio Sociolingüístico del Español de España y América" (PRESEEA), lo cual ha contribuido notablemente a explicar el comportamiento que presenta este fenómeno de variación fónica en diversos núcleos urbanos hispanohablantes, así como a conocer su difusión social y la distribución de variantes alofónicas principales: elisión total $[\varnothing]$ y realizaciones fricativas relajadas [’’] o plenas [ð].

En Andalucía, ámbito geográfico caracterizado dialectalmente por extremarse la caída de la fricativa intervocálica (Lapesa 506; Salvador 64, 74; Zamora 316), podemos afirmar que el debilitamiento y posterior pérdida de la -d- se produce hoy día en una enorme variedad de contextos fónicos, alcanzando gran penetración social, moderada entre los estratos de hablantes cultos y muy acusada en los sociolectos bajos. Nuestro estudio viene a sumarse a otros tantos realizados en el sur peninsular con la intención de exa-

1. Bustos establece tres etapas cronológicas en la pérdida de la dental fricativa: la primera tendría lugar durante la transición del latín al romance; la segunda abarcaría los siglos XIV y XVI, con la desaparición de la -d- en las desinencias verbales, y la última comenzaría en el siglo XVIII y continuaría.

2. Alba; Cedergren; D’Introno/Sosa; Gómez Molina (2005; 2013); Gómez Molina/Gómez Devís; Jiménez Fernández (2015; 2019); Malaver/Perdomo; Molina Martos (2001; 2006; 2009); Molina Martos/Paredes García; Moreno Fernández; Moya; Moya/García Wiedemann; Navarro Correa; Samper (1990; 1996; 2011); Samper/Pérez; Samper/Hernández; Villena (2003; 2008); Villena/Díaz/Ávila/Lasarte y Villena/Moya, entre otros. 
minar los factores que favorecen o restringen la elisión de la dental en posición intervocálica entre sujetos andaluces pertenecientes al habla urbana de Sevilla.

El propósito de esta investigación es analizar los factores lingüísticos, estilísticos y sociales que inciden en el proceso de mantenimiento y elisión de la /d/ intervocálica en el español hablado de la ciudad de Sevilla. ${ }^{3}$ Para ello, se han calculado las frecuencias de mantenimiento/elisión como fase previa al análisis de correlaciones bivariantes donde se ha medido el grado de dependencia entre las variables observadas. Se ha procedido a realizar también un análisis multivariante de regresión logística con el objeto de ver la interacción conjunta de todos los factores, así como para determinar el peso específico de cada variante en la elisión. Además de todo lo anterior, el trabajo se detiene en la observación del comportamiento lingüístico que presenta cada uno de los individuos, ante el fenómeno de elisión, en los dos entornos más extremos: entorno general y entorno - ado (Molina Martos/Paredes García).

Teniendo en cuenta lo anterior, hemos establecido las siguientes hipótesis de investigación:

a) Sobre el entorno general:

1. La pérdida de la /d/ intervocálica entre los hablantes del sociolecto culto de la ciudad de Sevilla se encuentra en un proceso más avanzado que el desarrollado en otras comunidades de habla pertenecientes a la zona geográfica del español castellano, caracterizadas por su conservadurismo fónico en contraste con la tendencia innovadora atestiguada en el sur peninsular.

2. Las variables lingüísticas son más determinantes en la variación de este fenómeno que las variables estilísticas o sociales.

3. Las vocales que preceden y siguen a la dental condicionan en gran medida la elisión, convirtiéndose de este modo el contorno vocálico en el más influyente de entre los factores lingüísticos.

4. La elisión de la /d/ se produce cuando la aproximante es parte constituyente del morfema, en tanto que se retiene cuando dicho sonido aparece en la estructura lexemática de la palabra. En este caso, la elisión se da en unidades lingüísticas muy utilizadas (todo, nada).

3. El mantenimiento comprende tanto las variantes con realización plena de la aproximante [ð] como las de realización débil o relajada $\left.{ }^{\natural}\right]$. 
5. La variación fonética se presenta de manera diferente según sea la categoría gramatical de la palabra afectada: pérdida acusada de la dental en participios verbales y adjetivos derivados, y conservación en el resto de clases de palabras. En aquellos la elisión se manifiesta intensamente en la terminación -ado, correspondiente a la primera conjugación verbal en contraste con la frecuente retención examinada en las formas participiales acabadas en -ido.

6. Entre los factores socioestilísticos que condicionan favorablemente la elisión se encuentran los jóvenes (variable edad), así como el hecho de que las entrevistas tuvieran lugar bajo un clima relajado e informal, con edad aproximada (variable tenor-edad) y con fuerte lazo de contacto (variable tenor-proximidad).

b) Sobre el entorno -ado:

7. En el entorno fónico - ado es donde el proceso de elisión está más avanzado, alejándose significativamente de la tendencia conservadora predominante en las modalidades de habla septentrional. Aquella se produce de forma mayoritaria en participios verbales y adjetivos, y en menor medida en el resto de categorías gramaticales.

\section{METODOLOGÍA}

El corpus oral empleado para llevar a cabo el análisis del proceso de mantenimiento y elisión de la /d/ intervocálica se compone de 24 entrevistas semidirigidas realizadas a informantes del sociolecto alto (estudios superiores) de la ciudad de Sevilla, seleccionados mediante un muestreo por cuotas de asignación uniforme según sexo y edad, con 4 individuos por casilla. ${ }^{4}$ Se registraron todas las ocurrencias con -d- en contexto intervocálico (v_v) halladas durante los cinco minutos iniciales de la grabación de la entrevista, los cinco del medio y los cinco del final. ${ }^{5}$

Para el estudio del debilitamiento y pérdida de la consonante dental hemos tenido en cuenta dos variantes de la variable dependiente, que reflejan dos momentos del desgaste de la dental: variante elidida, con cero fonético [Ø], y variante mantenida, ya fuera en su articulación como aproximante plena [ð] o

4. Consta de 12 mujeres y 12 hombres distribuidos en tres grupos de edad (primera generación, 20 a 34 años; segunda generación, entre 35 y 54 años, y tercera generación: 55 años en adelante).

5. Se excluyen los casos donde a la /d/ le precede una semivocal ("raudo") o le sigue una semiconsonante ("estudio"). Como se ha advertido en otras investigaciones similares (Alba 7), en ese contexto la conservación del segmento dental no presenta excepción alguna. 
relajada $\left.{ }^{\gamma}\right]$. En cuanto a las variables independientes, se consideraron las siguientes: ${ }^{6}$

a) Lingüísticas: posición del acento, número de sílabas de la palabra donde aparece la dental, estructura acentual de la palabra, entorno vocálico previo, entorno vocálico posterior, entorno consonántico en la palabra, entorno consonántico secuencial, categoría léxica, categoría gramatical de la palabra donde se encuentra la dental, homofonía, funcionalidad, presencia de la dental en el límite morfemático, difusión léxica y asimilación al turno de palabra anterior.

b) Estilísticas: tenor y edad, tenor y proximidad, grado de especialización del tema que se trata durante la entrevista y fase de interacción.

c) Sociales: sexo y edad.

Dentro del estudio cuantitativo se ha efectuado un análisis de correlaciones bivariantes en el entorno general entre la variable dependiente y las 20 variables independientes (lingüísticas, estilísticas y sociales), señaladas más arriba, mediante la aplicación del programa estadístico SPSS (versión 15.0). Con ello hemos obtenido unas tablas de contingencia en las que se detallan los valores de las frecuencias absolutas y relativas de cada correlación junto con las pruebas de significación estadística de los resultados. Posteriormente hemos empleado otro programa estadístico, el GoldVarb X (Sankoff/Tagliamonte/Smith), a fin de realizar el análisis multivariable de regresión logística que nos permita calcular la probabilidad de incidencia de los distintos grupos de factores sobre la variable dependiente.

\section{RESUlTADOS}

\section{Análisis de la variable /d/ intervocálica según los entornos fónicos}

Hemos establecido cuatro entornos fónicos para comprobar hasta qué punto estos pueden llegar a condicionar la retención o pérdida de nuestra variable

6. Las variables fueron seleccionadas del documento "Análisis de la /d/ intervocálica. Propuesta de codificación", elaborado por los equipos PRESEEA para el análisis de la dental sonora (<preseea.linguas.net/metodología>). Quedaron excluidas de nuestro análisis algunas otras variables (nivel de estudio, modo de vida, lengua habitual, etc.) por no ajustarse a las características de nuestra población o bien por presentar escasa aportación científica para la investigación. En el caso del nivel de estudios, este resultaba irrelevante pues todos los hablantes procedían de estudios superiores. 
dependiente. En primer lugar, se analiza el entorno general (v_v) a partir del cual efectuamos el cálculo probabilístico global y en el que se incorporan todas las ocurrencias con -/d/- intervocálica recogidas del corpus general de datos, con un total de 2532 casos (abogado, además, ayuda, cada, edad, marido, nada, produce, pueden, quedo, realidad, tradición). En segundo lugar, pasamos al entorno restringido (v[+ acento]_v[- acento]), con 1785 casos, constituido casi exclusivamtente por palabras paroxítonas en donde el sonido dental va precedido de una vocal acentuada (agrada, apellido, casado, dado, mercado, todo, venido). A continuación, el estudio se detiene en el entorno morfemático. Aquí se computan los contextos fónicos en que la dental ocupa la parte morfemática de la palabra (acostumbrada, alumnado, entidad, metido); este corpus consta de 1058 casos. Finalmente, en el entorno (-ado), el contexto más restrictivo de todos pues únicamente reúne aquellos casos en los cuales el segmento dental forma parte de la terminación - ado, hallamos un total de 521 palabras (aficionado, empleado, pasado).

\begin{tabular}{l|c|c|c|c|c} 
& \multicolumn{2}{c|}{ VARIANTE CERo [Ø] } & \multicolumn{2}{c|}{ VARIANTE MANTENIDA [d] } & TotAL \\
\cline { 2 - 6 } & $\mathrm{N}$ & $\%$ & $\mathrm{~N}$ & $\%$ & $\mathrm{~N}$ \\
\hline Entorno general & 457 & 18.0 & 2075 & 82.0 & 2532 \\
\hline Entorno restringido & 449 & 25.3 & 1136 & 74.7 & 1785 \\
\hline Entorno morfemático & 371 & 35.1 & 687 & 64.9 & 1058 \\
\hline Entorno propicio (-ado) & 363 & 69.7 & 158 & 30.3 & 521 \\
\hline
\end{tabular}

Tabla 1. Elisión y mantenimiento de la /d/ según los entornos

Según puede observarse en la tabla 1, apreciamos claramente cómo los valores porcentuales de la elisión aparecen escalonados de modo ascendente conforme pasamos del entorno general a los siguientes: $18 \%, 25.3 \%, 35.1 \%$ y $69.7 \%$. Si nos fijamos, en cambio, en los resultados de la retención, comprobamos que la tendencia lógicamente se invierte hacia unos porcentajes que descienden progresivamente, de un $82 \%$ en el entorno general a un $30.3 \%$ en el propicio (-ado). Además, solo es en el entorno más restrictivo (-ado) donde el porcentaje de elisiones supera al de conservación de la dental (69.7\% frente a $30.3 \%$ ). En el gráfico siguiente pueden corroborarse, efectivamente, las progresiones advertidas. 


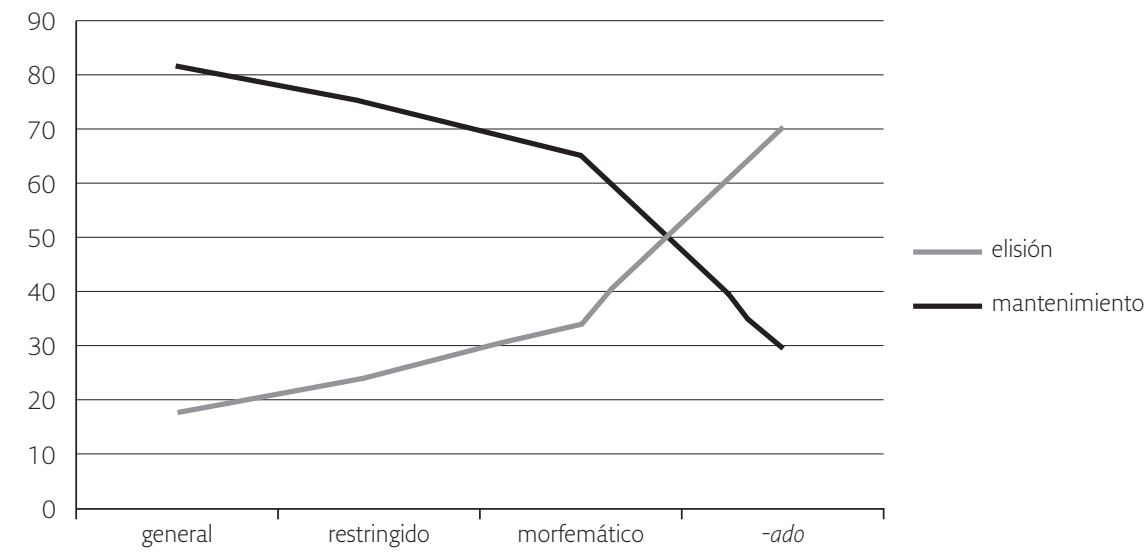

Gráfico 1. Porcentaje de elisión y mantenimiento de /d/ según los entornos

\section{Variables lingüísticas}

Mostramos seguidamente los resultados obtenidos tras realizar el análisis estadístico de correlaciones bivariantes por el cual hemos medido la relación entre variables. ${ }^{7}$ En todos los casos considerados, hubo correlación entre la producción de la variable dependiente y las variables lingüísticas.

Posición del acento

Chi $^{2}=214.039$ (4); Sig.: 0.000; v de Cramer: 0.291; Sig.: 0.000

\begin{tabular}{l|r|r|r|r|c}
\hline & \multicolumn{2}{c|}{ ELIIÓN } & \multicolumn{2}{c}{ MANTENIMIENTO } & TOTAL \\
\cline { 2 - 6 } & $\mathrm{N}$ & $\%$ & $\mathrm{~N}$ & $\%$ & $\mathrm{~N}$ \\
\hline Procede mediatamente (rápiDo) & 0 & 0.0 & 41 & 100 & 41 \\
\hline Procede inmediatamente (toDo) & 454 & 25.1 & 1352 & 74.9 & 1806 \\
\hline Sigue mediatamente (roDearé) & 0 & 0.0 & 43 & 100 & 43 \\
\hline Sigue inmediatamente (aDemás) & 1 & 0.6 & 159 & 99.4 & 160 \\
\hline Sílaba tónica (peDimos) & 2 & 0.4 & 480 & 99.6 & 482 \\
\hline
\end{tabular}

7. Para determinar la existencia o no de relación entre dos variables se realizan diferentes pruebas de significación estadística. Se trata de comprobar si las variables independientes influyen en la variación de la variable dependiente. Para comprobar la existencia o no de asociación entre ellas se utiliza el coeficiente estadístico ji cuadrado de Pearson y, por otro lado, para averiguar la intensidad de dicha asociación recurrimos al coeficiente $\mathrm{V}$ de Cramer (cuyos valores son entre 0 y 1 ). En cuanto al valor de $p$, que evalúa si el valor estadístico ji cuadrado es significativo o no, debe interpretarse de la siguiente manera: si es menor de 0.05 se rechaza la hipótesis nula o de independencia entre las variables en favor de la hipótesis alternativa o hipótesis de asociación entre las variables. 
JIMÉNEZ FERNÁNDEZ. VARIACIÓN FONOLÓGICA DE LA /d/ INTERVOCÁLICA EN SEVILLA

Número de sílabas

Chi $^{2}=90.819$ (2); Sig.: 0.000; v de Cramer: 0.189; Sig.: 0.000

\begin{tabular}{|c|c|c|c|c|c|}
\hline & \multicolumn{2}{|c|}{ ELISIÓN } & \multicolumn{2}{|c|}{ MANTENIMIENTO } & TOTAL \\
\hline & $\mathrm{N}$ & $\%$ & $\mathrm{~N}$ & $\%$ & N \\
\hline Bisílaba & 79 & 8.5 & 848 & 91.5 & 927 \\
\hline Trisílaba & 187 & 24.6 & 573 & 75.4 & 760 \\
\hline Polisílaba & 191 & 22.6 & 654 & 77.4 & 845 \\
\hline
\end{tabular}

\section{Estructural acentual}

Chi $^{2}=112.200$ (2); Sig.: 0.000; v de Cramer: 0.211; Sig.: 0.000

\begin{tabular}{|c|c|c|c|c|c|}
\hline & \multicolumn{2}{|c|}{ ELISIÓN } & \multicolumn{2}{|c|}{ MANTENIMIENTO } & TOTAL \\
\hline & N & $\%$ & N & $\%$ & N \\
\hline Proparoxítona & 1 & 1.5 & 64 & 98.5 & 65 \\
\hline Paroxítona & 456 & 21.7 & 1643 & 78.3 & 2099 \\
\hline Oxítona & 0 & 0.0 & 368 & 100 & 368 \\
\hline
\end{tabular}

\section{Entorno vocálico previo}

Chi $^{2}=711.396$ (9); Sig.: 0.000; v de Cramer: 0.530; Sig.: 0.000

\begin{tabular}{|c|c|c|c|c|c|}
\hline & \multicolumn{2}{|c|}{ ELISIÓN } & \multicolumn{2}{|c|}{ MANTENIMIENTO } & \multirow{2}{*}{$\frac{\text { TOTAL }}{\mathrm{N}}$} \\
\hline & N & $\%$ & N & $\%$ & \\
\hline Vocal átona [i] & 1 & 0.4 & 239 & 99.6 & 240 \\
\hline Vocal átona [u] & 0 & 0.0 & 24 & 100 & 24 \\
\hline Vocal átona [e] & 0 & 0.0 & 153 & 100 & 153 \\
\hline Vocal átona [o] & 0 & 0.0 & 139 & 100 & 139 \\
\hline Vocal átona [a] & 4 & 2.4 & 163 & 97.6 & 167 \\
\hline Vocal tónica [í] & 25 & 6.1 & 383 & 93.9 & 408 \\
\hline Vocal tónica [ú] & 0 & 0.0 & 21 & 100 & 21 \\
\hline Vocal tónica [é] & 0 & 0.0 & 214 & 100 & 214 \\
\hline Vocal tónica [ó] & 33 & 10.4 & 283 & 89.6 & 316 \\
\hline Vocal tónica [á] & 394 & 46.4 & 456 & 53.6 & 850 \\
\hline
\end{tabular}




\section{Entorno vocálico posterior}

Chi $^{2}=492.501$ (9) Sig.: 0.000 V de Cramer: 0.441; Sig.: 0.000

\begin{tabular}{l|c|c|c|c|c} 
& \multicolumn{2}{c}{ ELIón } & \multicolumn{2}{c|}{ MANTENIMIENTO } & TotAL \\
\cline { 2 - 6 } & $\mathrm{N}$ & $\%$ & $\mathrm{~N}$ & $\%$ & $\mathrm{~N}$ \\
\hline Vocal átona [i] & 0 & 0.0 & 69 & 100 & 69 \\
\hline Vocal átona [u] & 0 & 0.0 & 17 & 100 & 17 \\
\hline Vocal átona [e] & 2 & 0.8 & 237 & 99.2 & 239 \\
\hline Vocal átona [o] & 422 & 36.4 & 737 & 63.6 & 1159 \\
\hline Vocal átona [a] & 30 & 5.3 & 536 & 94.7 & 566 \\
\hline Vocal tónica [í] & 2 & 2.6 & 75 & 97.4 & 77 \\
\hline Vocal tónica [ú] & 0 & 0.0 & 7 & 100 & 7 \\
\hline Vocal tónica [é] & 0 & 0.0 & 73 & 100 & 73 \\
\hline Vocal tónica [ó] & 1 & 1.9 & 51 & 98.1 & 52 \\
\hline Vocal tónica [á] & 0 & 0.0 & 273 & 100 & 273 \\
\hline
\end{tabular}

\section{Entorno consonántico de la palabra}

Chi $^{2}=18.197$ (4) Sig.: 0.001; v de Cramer: 0.085; Sig.: 0.001

\begin{tabular}{l|c|c|c|c|c} 
& \multicolumn{2}{c|}{ ELIIÍN } & \multicolumn{2}{c}{ MANTENIMIENTO } & TotAL \\
\cline { 2 - 6 } & $\mathrm{N}$ & $\%$ & $\mathrm{~N}$ & $\%$ & $\mathrm{~N}$ \\
\hline No hay en el entorno /d/ & 437 & 18.4 & 1933 & 81.6 & 2370 \\
\hline /d/ previa realizada como [d] & 20 & 23.0 & 67 & 77.0 & 87 \\
\hline /d/ previa elidida & 0 & 0.0 & 1 & 100 & 7 \\
\hline /d/ posterior realizada como [d] & 0 & 0.0 & 60 & 100 & 60 \\
\hline$/ \mathrm{d} /$ posterior elidida & 0 & 0.0 & 14 & 100 & 14 \\
\hline
\end{tabular}




\section{Entorno consonántico secuencial}

Chi $^{2}=123.360$ (2) Sig.: 0.000; v de Cramer: 0.221; Sig.: 0.000

\begin{tabular}{|c|c|c|c|c|c|}
\hline & \multicolumn{2}{|c|}{ ELISIÓN } & \multicolumn{2}{|c|}{ MANTENIMIENTO } & \multirow{2}{*}{$\frac{\text { TOTAL }}{N}$} \\
\hline & N & $\%$ & N & $\%$ & \\
\hline No hay en el entorno /d/ & 217 & 17.4 & 1027 & 82.6 & 1244 \\
\hline Hay una o varias /d/ realizadas & 94 & 10.6 & 791 & 89.4 & 885 \\
\hline Hay una o varias /d/ elididas & 146 & 36.2 & 257 & 63.8 & 403 \\
\hline
\end{tabular}

\section{Categoría léxica}

Chi $^{2}=13.535$ (2) Sig.: 0.001; v de Cramer: 0.073; Sig.: 0.001

\begin{tabular}{l|c|c|c|c|c} 
& \multicolumn{2}{c|}{ Elión } & \multicolumn{2}{c|}{ MANTENIMIENTO } & TotAL \\
\cline { 2 - 6 } & $\mathrm{N}$ & $\%$ & $\mathrm{~N}$ & $\%$ & $\mathrm{~N}$ \\
\hline Extranjero & 0 & 0.0 & 0 & 0.0 & 0 \\
\hline Nombre propio & 0 & 0.0 & 55 & 100 & 55 \\
\hline Término & 0 & 0.0 & 5 & 100 & 5 \\
\hline Otros & 457 & 18.5 & 2015 & 81.5 & 2472 \\
\hline
\end{tabular}

\section{Categoría gramatical}

Chi $^{2}=410.348$ (6) Sig.: 0.000; v de Cramer: 0.403; Sig.: 0.000

\begin{tabular}{|c|c|c|c|c|c|}
\hline & \multicolumn{2}{|c|}{ ELISIÓN } & \multicolumn{2}{|c|}{ MANTENIMIENTO } & \multirow{2}{*}{$\frac{\text { TOTAL }}{\mathrm{N}}$} \\
\hline & N & $\%$ & N & $\%$ & \\
\hline Verbo-participio $^{7}$ & 204 & 43.5 & 265 & 56.5 & 469 \\
\hline Verbo (otras formas) ${ }^{2}$ & 1 & 0.3 & 341 & 99.7 & 342 \\
\hline Nombre & 67 & 9.2 & 663 & 90.8 & 730 \\
\hline Adjetivo $^{3}$ & 130 & 33.1 & 263 & 66.9 & 393 \\
\hline Pronombre & 29 & 11.1 & 233 & 88.9 & 262 \\
\hline Adverbio & 8 & 6.0 & 126 & 94.0 & 134 \\
\hline Determinante & 18 & 8.9 & 184 & 91.1 & 202 \\
\hline
\end{tabular}

1. Se incluye el participio de los tiempos compuestos de la conjugación verbal.

2. Se incluyen las formas personales del verbo.

3. Se incluyen adjetivos en forma de participio. 


\section{Homofonía}

Chi $^{2}=207.963$ (4) Sig.: 0.000; v de Cramer: 0.287; Sig.: 0.000

\begin{tabular}{|c|c|c|c|c|c|}
\hline & \multicolumn{2}{|c|}{ ELISIÓN } & \multicolumn{2}{|c|}{ MANTENIMIENTO } & \multirow{2}{*}{$\frac{\text { TOTAL }}{\mathrm{N}}$} \\
\hline & N & $\%$ & N & $\%$ & \\
\hline Ausencia de homofonía & 290 & 15.8 & 1547 & 84.2 & 1837 \\
\hline Homofonía entre nombre o adjetivo y participio & 111 & 54.7 & 92 & 45.3 & 203 \\
\hline Homofonía entre adjetivo y nombre & 4 & 10.5 & 34 & 89.5 & 38 \\
\hline Homofonía entre sustantivo y verbo & 0 & 0.0 & 28 & 100 & 28 \\
\hline Otros casos & 52 & 12.2 & 374 & 87.8 & 426 \\
\hline
\end{tabular}

\section{Funcionalidad}

Chi $^{2}=25.170$ (2) Sig.: 0.000; v de Cramer: 0.100; Sig.: 0.000

\begin{tabular}{|c|c|c|c|c|c|}
\hline & \multicolumn{2}{|c|}{ ELISIÓN } & \multicolumn{2}{|c|}{ MANTENIMIENTO } & \multirow{2}{*}{$\frac{\text { TOTAL }}{N}$} \\
\hline & N & $\%$ & N & $\%$ & \\
\hline No existe funcionalidad virtual & 439 & 19.2 & 1849 & 80.8 & 2288 \\
\hline $\begin{array}{l}\text { La /d/ marca virtualmente diferencia } \\
\text { semántica en un par mínimo de diferente } \\
\text { categoría morfológica }\end{array}$ & 18 & 11.0 & 146 & 89.0 & 164 \\
\hline $\begin{array}{l}\text { La /d/ marca virtualmente diferencia } \\
\text { semántica en un par mínimo de la misma } \\
\text { categoría morfológica }\end{array}$ & 0 & 0.0 & 80 & 100 & 80 \\
\hline
\end{tabular}

\section{Limite morfemático}

Chi $^{2}=369.320$ (1) Sig.: 0.000; v de Cramer: 0.382; Sig.: 0.000

\begin{tabular}{|c|c|c|c|c|c|}
\hline & \multicolumn{2}{|c|}{ ELISIÓN } & \multicolumn{2}{|c|}{ MANTENIMIENTO } & \multirow{2}{*}{$\frac{\text { TOTAL }}{N}$} \\
\hline & N & $\%$ & N & $\%$ & \\
\hline /d/ en el lexema & 82 & 5.6 & 1389 & 94.4 & 1471 \\
\hline /d/ en el morfema o participio & 375 & 35.3 & 686 & 64.7 & 1061 \\
\hline
\end{tabular}




\section{Difusión léxica}

Chi $^{2}=159.064$ (9) Sig.: 0.000; v de Cramer: 0.251; Sig.: 0.000

\begin{tabular}{l|c|c|c|c|c} 
& \multicolumn{2}{c}{ ELIÍ́N } & \multicolumn{2}{c|}{ MANTENIMIENTO } & TotAL \\
\cline { 2 - 6 } & $N$ & $\%$ & $N$ & $\%$ & $N$ \\
\hline Vida & 0 & 0.0 & 67 & 100 & 67 \\
\hline Además & 0 & 0.0 & 61 & 100 & 61 \\
\hline Todavía & 0 & 0.0 & 28 & 100 & 28 \\
\hline Cada & 0 & 0.0 & 44 & 100 & 44 \\
\hline Nada & 12 & 10.9 & 98 & 89.1 & 110 \\
\hline Quedar & 6 & 10.3 & 52 & 89.7 & 58 \\
\hline Poder & 1 & 0.4 & 230 & 99.6 & 231 \\
\hline Todo núcleo & 17 & 11.3 & 133 & 88.7 & 150 \\
\hline Todo modificador & 16 & 10.7 & 134 & 89.3 & 150 \\
\hline Otras & 405 & 24.8 & 1228 & 75.2 & 1633 \\
\hline
\end{tabular}

\section{Asimilación al turno de palabra anterior}

Chi $^{2}=31.469$ (2) Sig.: 0.000; v de Cramer: 0.111; Sig.: 0.000

\begin{tabular}{l|c|c|c|c|c}
\hline & \multicolumn{2}{c|}{ ELIÍN } & \multicolumn{2}{c|}{ MANTENIMIENTO } & TOTAL \\
\cline { 2 - 6 } & $\mathrm{N}$ & $\%$ & $\mathrm{~N}$ & $\%$ & $\mathrm{~N}$ \\
\hline $\begin{array}{l}\text { No se produjo ninguna aparición cercana } \\
\text { de /d/ en el turno anterior }\end{array}$ & 373 & 17.1 & 1810 & 82.9 & 2183 \\
\hline $\begin{array}{c}\text { En el turno de palabra anterior se produjeron } \\
\text { una o más ocurrencias de /d/ elidida }\end{array}$ & 49 & 36.0 & 87 & 64.0 & 136 \\
\hline $\begin{array}{l}\text { En el turno de palabra anterior se produjeron } \\
\text { una o más ocurrencias de /d/ realizada } \\
\text { como [d] }\end{array}$ & 35 & 16.4 & 178 & 83.6 & 213 \\
\hline
\end{tabular}

Tabla 2. Variables lingüísticas (entorno general) 
En cuanto a la posición del acento, el entorno lingüístico que más favorece la elisión se da cuando el acento precede inmediatamente a la sílaba donde aparece la /d/, con un $25.1 \%$. Se trata de un contexto donde encontramos palabras como abogado, cada, cambiado, dado, demasiado, estado, gustado, lado, nada, puede, sido, todo, vida, etc. El resto de contornos no propicia la desaparición de la dental. Se observan unos porcentajes muy bajos: $0.6 \%$ cuando el acento sigue inmediatamente a la sílaba donde se encuentra la dental (con un caso: alante por adelante) y $0.4 \%$ cuando la -d- se sitúa en la sílaba tónica (pescaíto por pescadito, en dos ocasiones). Cuando el acento se aleja de la sílaba que contiene la dental, ya la preceda (pérdidas, métodos, cómoda) o la siga mediatamente (educación, tradicional), no hallamos ningún ejemplo de elisión.

Según el número de sílabas, la elisión alcanza su valor porcentual más elevado en las palabras trisílabas (24.6\%) (cambiao por cambiado, estao por estado), si bien a escasa distancia del porcentaje de las polisílabas (22.6 \%) (abogao por abogado, complicao por complicado). Son las palabras bisílabas las que más resistencia ofrecen con respecto a la elisión, pese a recogerse entre ellas casos como todo(s), toda(s), nada, dado o lado, tan proclives a perder el sonido dental. Ciertamente, el hecho de tratarse de un corpus oral, perteneciente a informantes del sociolecto culto, ha influido notablemente en el mantenimiento de la /d/ (con un $91.5 \%$ ).

La estructura acentual nos muestra que son las palabras paroxítonas las que mayor incidencia tienen sobre la elisión (456 casos, 21.7 \%). Por su parte, las palabras proparoxítonas y oxítonas favorecen intensamente la retención, sobre todo las segundas (100\%).

Como es sabido, el contorno vocálico, que incluye los efectos que producen las vocales que preceden y siguen a la dental, resulta ser un factor determinante para su mantenimiento o elisión. En el entorno vocálico previo son las vocales tónicas las que propician la elisión de modo casi exclusivo (á, ó, i): [á] 394 casos, [ó] 33 y [í] 25. La jerarquía de estas vocales es la siguiente: [á] 394, 46.4 \%; [ó] 33, 10.4 \%; [í] 25, $6.1 \%$; [a] 4, 2.4 \%; [i] 1, 0.4 \%; resto $0 \%$.

En el entorno vocálico posterior el protagonismo recae sobre las vocales átonas, sin duda es la [o] la que más propicia la pérdida del segmento dental. La gradación se manifiesta de la siguiente forma: [o] 422, 36.4 \%; [a] 30, $5.3 \%$; [1́] 2, $2.6 \%$; [ó] 1, $1.9 \%$, [e] 2, $0.8 \%$; resto $0 \%$.

Si analizamos conjuntamente ambos entornos vocálicos, obtendremos los contextos fonéticos que exponemos en la siguiente tabla: 
JIMÉNEZ FERNÁNDEZ. VARIACIÓN FONOLÓGICA DE LA /d/ INTERVOCÁLICA EN SEVILLA

\begin{tabular}{l|r}
\hline [-ádo] & $370(81.0 \%)$ \\
\hline [-ódo] & $28(6.2 \%)$ \\
\hline [-áda] & $25(5.4 \%)$ \\
\hline [-ído] & $23(5.1 \%)$ \\
\hline [-óda] & $4(0.8 \%)$ \\
\hline [-ída] & $3(0.6 \%)$ \\
\hline [-adí] & $2(0.4 \%)$ \\
\hline [-ade] & $1(0.2 \%)$ \\
\hline [-adó] & $1(0.2 \%)$ \\
\hline Total & $457(100 \%)$ \\
\hline
\end{tabular}

* En los entornos [-ádo], [-ódo], [-áda], [-ído], [-óda] e [ída] se han incluido las terminaciones morfemáticas de plural.

Tabla 3. Porcentajes entornos vocálicos*

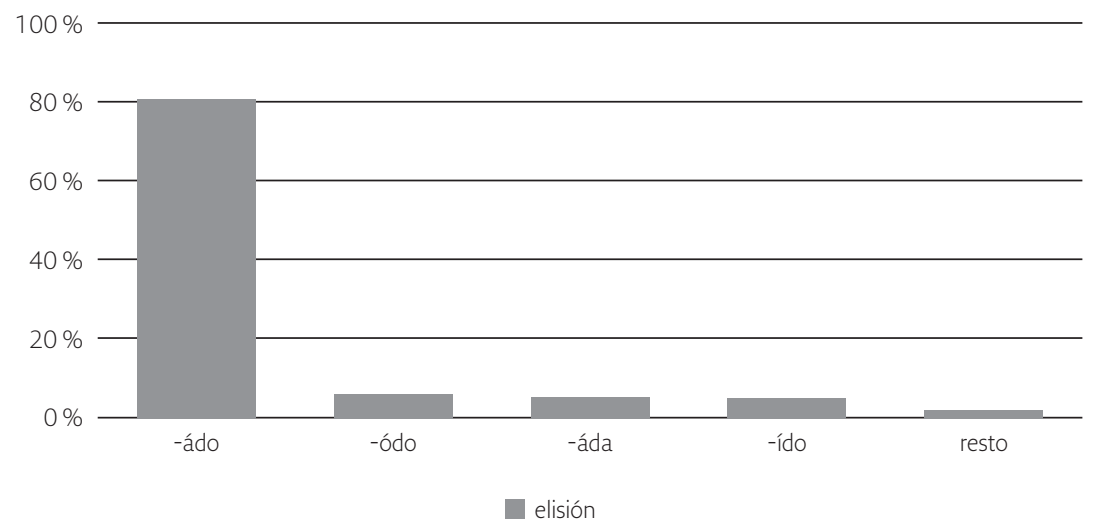

Gráfico 2. Contornos vocálicos con elisión de la dental

Estos resultados confirman que es el contorno [-ádo] el de mayor incidencia en el proceso de elisión. Le siguen, en orden decreciente, [-ódo], [-áda], [-ído], y ya con valores muy reducidos: [-óda], [-ída], [-adí], [-ade] y [-adó]. El resto de contextos rechaza la desaparición de la /d/. 
Con la variable entorno consonántico de la palabra se intenta demostrar si la constitución fónica de la palabra se encuentra correlacionada con la retención o pérdida del sonido dental. Como puede observarse, nuestros resultados corroboran que la elisión únicamente tiene lugar, o bien cuando existe una /d/ previa realizada como [d] (adaptado > adaptao, considerados $>$ consideraos, cuidado $>$ cuidao, educado > educao, quedado > quedao...), con el $23 \%$, o bien si en el entorno consonántico de la palabra no hay /d/ intervocálica (18.4\%): abrigada, acostumbrado, dictado, nada, todo, etc.

Mediante el análisis del entorno consonántico secuencial tratamos de conocer si la existencia o no de realizaciones elididas dentro de un grupo fónico influye en la variable dependiente. Los resultados obtenidos demuestran que la elisión sucede en todos los entornos considerados. Si en el contexto aparecen /d/ elididas se produce un mayor porcentaje de elisión (36.2\%), mientras que si aparecen /d/ pronunciadas el porcentaje desciende considerablemente hasta el $10.6 \%$. En cuanto a la categoría léxica, se comprueba que ante nombres propios y términos marcados el rechazo a la elisión es total (Antártida, biodiversidad, Cádiz, Estados Unidos, Inmaculada), hecho que contrasta con los casos incluidos bajo la categoría otros (términos no marcados), donde la pérdida del sonido dental alcanza el $18.5 \%$.

Con respecto a la categoría gramatical, el participio (43.5\%) y el adjetivo (33.1\%) son las categorías que más favorecen la pérdida de la dental. Entre ambas alcanzan el 73.08 \% de los casos de elisión (334/457). El contorno vocálico que más propicia la elisión en estas dos clases es [-ádo]: aprovechado, asustados, cambiado, dado, estado, pasado, tocado, etc. Mantienen, por el contrario, la variante dental, con unos porcentajes muy elevados, el verbo ( $99.7 \%$ ), el adverbio (94\%), los determinantes (91.1\%), el nombre (90.8\%) y el pronombre $(88.9 \%)$. Si nos centramos en la categoría verbal, el único testimonio recogido es el de queó por quedó, producido en un momento discursivo sumamente relajado. En realizaciones tan frecuentes en cualquier manifestación oral como todo, toda y nada, constatamos que los hablantes del sociolecto culto rechazan claramente reducciones fonéticas del tipo to (por todo), toa (por toda) o na (por nada).

En general, y tal como se puede deducir del gráfico siguiente, el proceso de elisión de la /d/ solo se muestra con fuerza ante las formas de participio, aun cuando no llegue siquiera al $50 \%$ de los casos. 


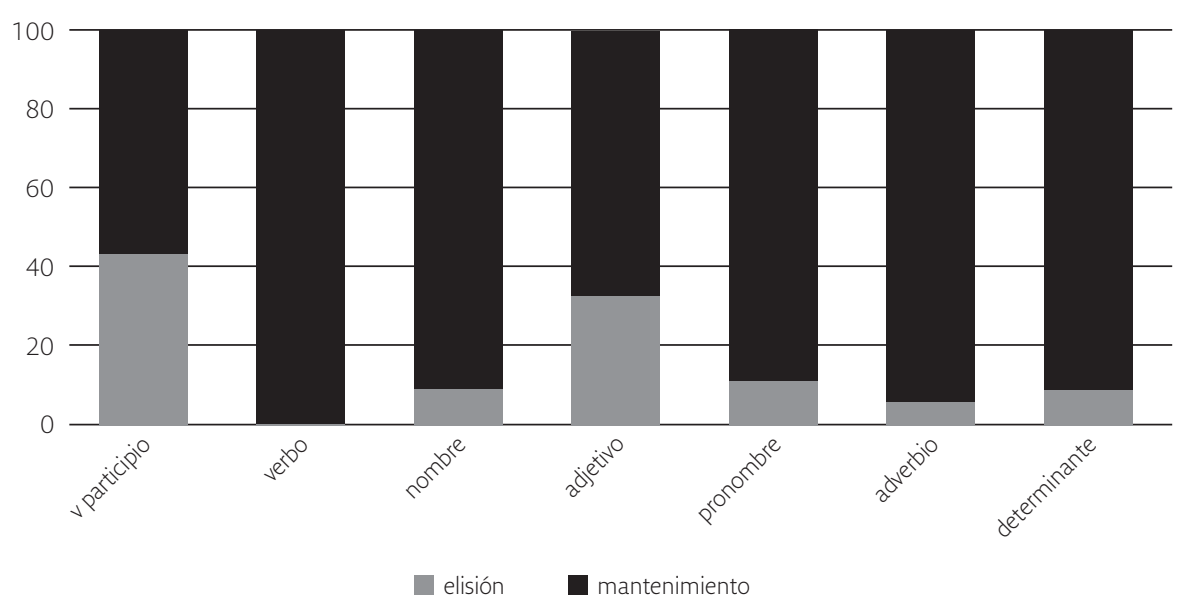

Gráfico 3. Porcentajes elisión/mantenimiento

Mediante la variable gramatical homofonía queremos averiguar si este fenómeno influye en la elisión de la dental. Los casos de homofonía entre nombre o adjetivo y participio (alumbrado, estado) ofrecen el índice porcentual más elevado (54.7 \%), en tanto que la homofonía entre adjetivo y nombre y otros casos de homofonía, que engloba palabras tan frecuentes como todo y nada, solo llegan al $10.5 \%$ y $12.2 \%$, respectivamente.

En cuanto a la variable funcionalidad, los valores obtenidos señalan que cuando no existe funcionalidad virtual la frecuencia de pérdida de la dental supone un $19.2 \%$, en tanto que si la /d/ marca diferencia semántica en un par mínimo de diferente categoría gramatical (todos/tos, comida/comía) la elisión es del $11 \%$. Esta, sin embargo, se frena, llegando a ser inexistente, cuando la /d/ marca diferencia semántica en un par de unidades léxicas de la misma categoría gramatical (vida/vía).

Con la variable limite morfemático examinamos si el sonido dental forma parte de la raíz léxica de la palabra o bien del morfema. Según se desprende de nuestros datos, la elisión se produce mayoritariamente cuando la /d/ se integra como constituyente del morfema $(35.3 \%)$ frente a un número bastante menor de ocurrencias donde la dental forma parte del lexema (5.6\%).

Respecto al listado de palabras de uso frecuente (variable difusión léxica), vemos que únicamente se realiza la pérdida de la /d/ en palabras como nada $(10.9 \%)$, quedar $(10.3 \%)$, todo -núcleo- $(11.3 \%)$ y todo -modificador$(10.7 \%)$, con unas frecuencias muy bajas. Por su parte, la retención del sonido dental es categórica en los casos de vida, además, todavía y cada. 
Finalmente, la asimilación al turno anterior, última variable lingüística que describimos, atiende a la posible influencia en la producción discursiva del hablante el hecho de que en el turno de palabra anterior hayan aparecido, en mayor o menor medida, casos de retención o de no pronunciación de otras dentales. Nuestros datos corroboran que el mantenimiento de la /d/ se impone en todas las opciones estudiadas. La variante elidida se frena menos (36 \%) cuando en el turno anterior hay dentales omitidas. No obstante, este condicionamiento del modo de hablar del entrevistador sobre el del informante surge en muy pocos casos con respecto a las frecuencias totales (136/2 532).

\section{Variables estilísticas}

En cuanto al comportamiento de las variables diafásicas sobre la dental, podemos apuntar que solo la fase de la interacción ha mostrado unos valores estadísticos no significativos. Veamos a continuación los detalles más relevantes del resto de factores.

Tenor y edad

Chi $^{2}=32.712$ (2) Sig.: 0.000; v de Cramer: 0.114; Sig.: 0.000

\begin{tabular}{l|c|c|c|c|c}
\hline & \multicolumn{2}{c|}{ ELIÓN } & \multicolumn{2}{c|}{ MANTENIIENTO } & TOTAL \\
\cline { 2 - 6 } & $\mathrm{N}$ & $\%$ & $\mathrm{~N}$ & $\%$ & $\mathrm{~N}$ \\
\hline Solidaridad (edad aproximada) & 233 & 21.5 & 849 & 78.5 & 1082 \\
\hline I $<$ E (informante menor que entrevistador) & 13 & 5.7 & 214 & 94.3 & 227 \\
\hline I $>$ E (informante mayor que entrevistador) & 211 & 17.3 & 1012 & 82.7 & 1223 \\
\hline
\end{tabular}

\section{Tenor y proximidad}

Chi $^{2}=10.303$ (2) Sig.: 0.006; v de Cramer: 0.064; Sig.: 0.006

\begin{tabular}{l|c|c|c|c|c}
\hline & \multicolumn{2}{c|}{ Elsión } & \multicolumn{2}{c|}{ MANTENIIENTO } & TOtAL \\
\cline { 2 - 6 } & $\mathrm{N}$ & $\%$ & $\mathrm{~N}$ & $\%$ & $\mathrm{~N}$ \\
\hline Insider (amigo, pariente, vecino, compañero) & 392 & 19.3 & 1644 & 80.7 & 2036 \\
\hline Outsider (conocido, lazo débil de contacto) & 46 & 13.5 & 295 & 86.5 & 341 \\
\hline Relación surgida en la entrevista & 19 & 12.3 & 136 & 87.7 & 155 \\
\hline
\end{tabular}


Especialización

Chi $^{2}=14.281$ (2) Sig.: 0.001; v de Cramer: 0.075; Sig.: 0.001

\begin{tabular}{|c|c|c|c|c|c|}
\hline & \multicolumn{2}{|c|}{ ELISIÓN } & \multicolumn{2}{|c|}{ MANTENIMIENTO } & \multirow{2}{*}{$\frac{\text { TOTAL }}{N}$} \\
\hline & N & $\%$ & N & $\%$ & \\
\hline No técnico: vida cotidiana, familia, amigos & 349 & 16.7 & 1738 & 83.3 & 2087 \\
\hline Técnico: trabajo, afición, estudios & 103 & 24.1 & 324 & 75.9 & 427 \\
\hline Metalingüístico & 5 & 27.8 & 13 & 72.2 & 18 \\
\hline
\end{tabular}

Fase de interacción

Chi $^{2}=5.520$ (2) Sig.: 0.063; v de Cramer: 0.047; Sig.: 0.063

\begin{tabular}{|c|c|c|c|c|c|}
\hline & \multicolumn{2}{|c|}{ ELISIÓN } & \multicolumn{2}{|c|}{ MANTENIMIENTO } & \multirow{2}{*}{$\frac{\text { TOTAL }}{N}$} \\
\hline & N & $\%$ & N & $\%$ & \\
\hline Comienzo & 120 & 15.4 & 659 & 84.6 & 779 \\
\hline Intermedio & 172 & 19.6 & 704 & 80.4 & 876 \\
\hline Final & 165 & 18.8 & 712 & 81.2 & 877 \\
\hline
\end{tabular}

Tabla 4. Variables estilísticas (entorno general)

La variable tenor-edad determina si la edad del informante y del entrevistador incide sobre la dental. Como puede comprobarse en la tabla n. ${ }^{\circ}$ 4, la elisión se ve favorecida cuando los interlocutores poseen una edad aproximada $(21.5 \%)$ así como cuando el informante es mayor que el entrevistador (17.3\%). La retención, en cambio, se da con mucha fuerza $(94.3 \%)$ en caso de que el informante sea menor que el entrevistador.

Respecto a la relación de proximidad entre los interlocutores (tenor-proximidad), el índice de porcentaje más alto de elisión se corresponde con entrevistas donde aquellos presentaban un fuerte grado de parentesco (amigos, vecinos, compañeros, parientes), con un $19.3 \%$, seguidos por los casos en que los participantes se conocían débilmente $(13.5 \%)$ o bien no se conocían con anterioridad a la grabación (12.3\%). Obsérvese cómo la elisión va disminuyendo conforme la relación entre informante y entrevistador posee lazos personales menos estrechos.

La variable especialización se detiene en los distintos temas de conversación que han ido surgiendo durante el desarrollo discursivo de la entrevista. El 
$82.4 \%$ de casos de /d/ contabilizados pertenece a temáticas de carácter no técnico. Aquí la retención alcanza el $83.3 \%$ frente al $16.7 \%$ de elisiones.

El propósito de la última variable estilística (fase de interacción) es descubrir si conforme avanza el desarrollo de la entrevista se va produciendo, al mismo tiempo, un mayor relajamiento emocional y espontaneidad expresiva por parte del entrevistado, que permita igualmente un aumento progresivo de casos de no articulación de la /d/. Como hemos dicho con anterioridad, nuestro cálculo estadístico arroja unos valores no significativos en la asociación entre esta variable y la /d/. No obstante, merece la pena fijarnos en los datos cosechados, pues estos constatan un incremento de la elisión en las últimas fases con respecto a los primeros minutos de comienzo de la entrevista, en la que el informante se siente más tenso y distante frente a la interacción comunicativa.

\section{Variables sociales}

Los factores sociales examinados son el sexo y la edad. El primero, a diferencia de lo que sucede en otras investigaciones, no es significativo estadísticamente. Detengámonos en cada una de ellas.

Sexo

Chi $^{2}=0.557$ (1) Sig.: 0.456; v de Cramer: 0.015; Sig.: 0.456

\begin{tabular}{|c|c|c|c|c|c|}
\hline & \multicolumn{2}{|c|}{ ELISIÓN } & \multicolumn{2}{|c|}{ MANTENIMIENTO } & TOTAL \\
\hline & N & $\%$ & N & $\%$ & N \\
\hline Hombres & 220 & 18.7 & 959 & 81.3 & 1179 \\
\hline Mujeres & 237 & 17.5 & 1116 & 82.5 & 1353 \\
\hline
\end{tabular}

\section{Edad}

Chi $^{2}=34.732$ (2) Sig.: 0.000; v de Cramer: 0.117; Sig.: 0.000

\begin{tabular}{l|c|c|c|c|c}
\hline & \multicolumn{2}{c|}{ ELIIÓN } & \multicolumn{2}{c}{ MANTENIMIENTO } & TOTAL \\
\cline { 2 - 6 } & $\mathrm{N}$ & $\%$ & $\mathrm{~N}$ & $\%$ & $\mathrm{~N}$ \\
\hline Primera generación (20-34 años) & 197 & 23.2 & 652 & 76.8 & 849 \\
\hline Segunda generación (35-54 años) & 90 & 11.9 & 667 & 88.1 & 757 \\
\hline Tercera generación (55-adelante) & 170 & 18.4 & 756 & 81.6 & 926 \\
\hline
\end{tabular}

Tabla 5. Variables sociales (entorno general) 
En cuanto a la variable sexo, observamos que en nuestro corpus los hombres y las mujeres ofrecen unos resultados de elisión muy próximos, si bien algunas décimas más en el caso de los hombres. Por su parte, según la edad, los más jóvenes son quienes más eliden la dental (23.2\%), seguidos de los hablantes de la tercera generación (18.4 \%) y los de la segunda generación (11.9 \%). Por tanto, jóvenes y mayores son los grupos que muestran más casos de elisión, por encima de los cosechados por los sujetos de edad intermedia.

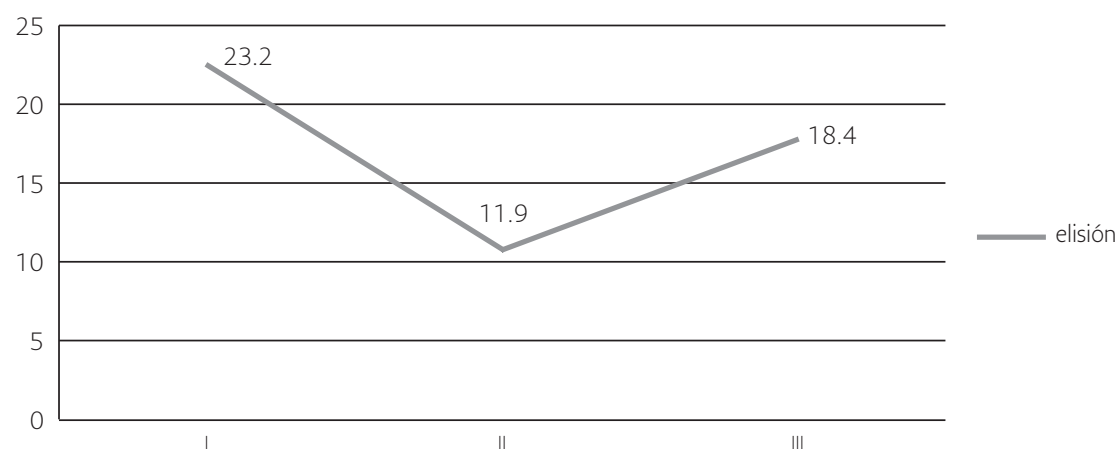

Gráfico 4. Porcentaje de elisión según grupo generacional

Si correlacionamos nuestras dos variables sociales con la elisión y el mantenimiento de la dental sonora (entorno general), obtenemos unos resultados estadísticos significativos cuyos porcentajes representamos en el gráfico 5.

Sexo y edad

Chi $^{2}=39.513$ (5) Sig.: 0.000; v de Cramer: 0.125; Sig.: 0.000

\begin{tabular}{l|c|c|c|c|c} 
& \multicolumn{2}{c}{ ELIÍN } & \multicolumn{2}{c}{ MANTENIMIENTO } & TOTAL \\
\cline { 2 - 6 } & $\mathrm{N}$ & $\%$ & $\mathrm{~N}$ & $\%$ & $\mathrm{~N}$ \\
\hline Hombres-I generación & 110 & 25.8 & 316 & 74.2 & 426 \\
\hline Hombres-II generación & 38 & 11.4 & 296 & 88.6 & 334 \\
\hline Hombres-III generación & 72 & 17.2 & 347 & 82.8 & 419 \\
\hline Mujeres-I generación & 87 & 20.6 & 336 & 79.4 & 423 \\
\hline Mujeres-II generación & 52 & 12.3 & 371 & 87.7 & 423 \\
\hline Mujeres-III generación & 98 & 19.3 & 409 & 80.7 & 507 \\
\hline
\end{tabular}

Tabla 6. Relación entre sexo y edad 


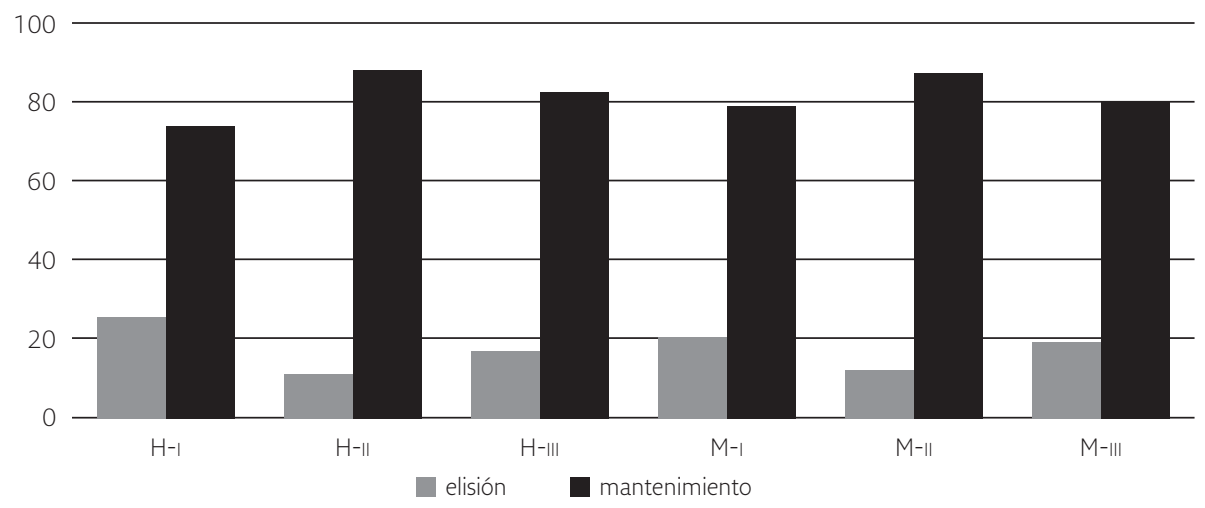

Gráfico 5. Porcentajes elisión/mantenimiento según sexo y edad (entorno general)

Como puede apreciarse en el gráfico 6, la elisión tanto en hombres como en mujeres se presenta conforme a un patrón en forma de uve, esto es, la segunda generación, la intermedia, se sitúa por debajo de los informantes de las generaciones de jóvenes y mayores, los cuales se posicionan por encima de aquella.

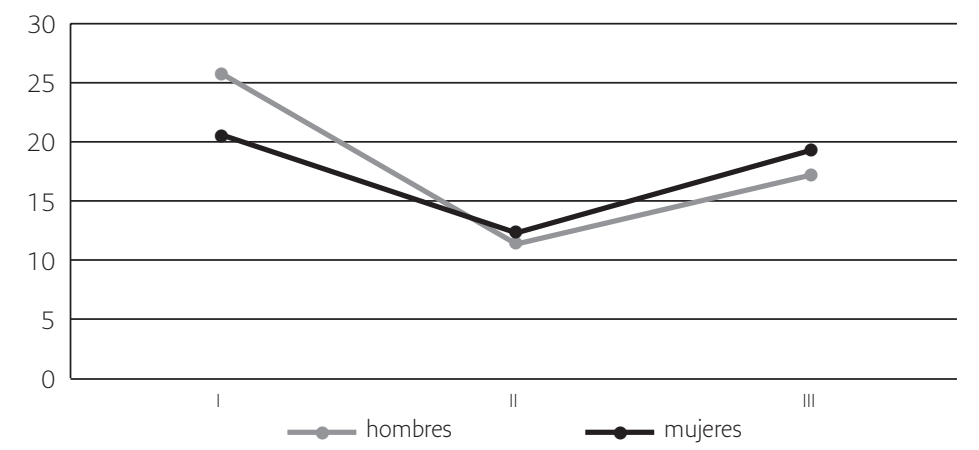

Gráfico 6. Porcentaje elisión por sexo y edad (entorno general)

\section{Análisis de la variación individual}

Una vez hecho el análisis bivariante de los factores lingüísticos y socioestilísticos, conviene detenerse en examinar el comportamiento fonético de cada uno de los individuos con respecto al fenómeno de la elisión de la dental porque es "la actitud individual hacia la variable lingüística la que mejor explica la variación" (Molina Martos/Paredes García 87). Siguiendo el modelo propuesto por Villena/Díaz/Ávila/Lasarte (330-31), establecemos a continuación la gradación de la elisión en los cuatro entornos. 
JIMÉNEZ FERNÁNDEZ. VARIACIÓN FONOLÓGICA DE LA /d/ INTERVOCÁLICA EN SEVILLA

\begin{tabular}{|c|c|c|c|c|c|c|}
\hline HABLANTES & \begin{tabular}{|l|} 
GRUPOS \\
ETARIOS
\end{tabular} & SEXo & General & RESTRINGIDO & MoRFEMÁTICO & -ado \\
\hline 1 & I & hombre & 0.02 & 0.03 & 0.05 & 0.13 \\
\hline 2 & I & hombre & 0.41 & 0.60 & 0.70 & 0.93 \\
\hline 3 & I & hombre & 0.42 & 0.50 & 0.76 & 0.97 \\
\hline 4 & I & hombre & 0.09 & 0.17 & 0.25 & 0.67 \\
\hline 5 & I & mujer & 0.29 & 0.39 & 0.43 & 0.96 \\
\hline 6 & I & mujer & 0.06 & 0.08 & 0.10 & 0.20 \\
\hline 7 & I & mujer & 0.14 & 0.17 & 0.24 & 0.57 \\
\hline 8 & I & mujer & 0.30 & 0.46 & 0.56 & 0.92 \\
\hline & & & media 0.22 & media 0.30 & media 0.39 & media 0.67 \\
\hline 9 & $\|$ & hombre & 0.13 & 0.22 & 0.30 & 0.60 \\
\hline 10 & $\|$ & hombre & 0.13 & 0.18 & 0.22 & 0.42 \\
\hline 11 & $\|$ & hombre & 0.16 & 0.20 & 0.33 & 0.52 \\
\hline 12 & $\|$ & hombre & 0.02 & 0.02 & 0.06 & 0.08 \\
\hline 13 & $\|$ & mujer & 0.09 & 0.13 & 0.21 & 0.56 \\
\hline 14 & $\|$ & mujer & 0.06 & 0.08 & 0.13 & 0.26 \\
\hline 15 & $\|$ & mujer & 0.14 & 0.18 & 0.29 & 0.72 \\
\hline 16 & $\|$ & mujer & 0.21 & 0.34 & 0.47 & 0.96 \\
\hline & & & media 0.12 & media 0.17 & media 0.25 & media 0.52 \\
\hline 17 & III & hombre & 0.09 & 0.12 & 0.15 & 0.32 \\
\hline 18 & III & hombre & 0.18 & 0.21 & 0.31 & 0.85 \\
\hline 19 & III & hombre & 0.21 & 0.31 & 0.50 & 0.85 \\
\hline 20 & III & hombre & 0.21 & 0.36 & 0.51 & 0.89 \\
\hline 21 & III & mujer & 0.15 & 0.20 & 0.31 & 0.80 \\
\hline 22 & III & mujer & 0.28 & 0.37 & 0.42 & 0.81 \\
\hline 23 & III & mujer & 0.20 & 0.29 & 0.36 & 0.87 \\
\hline 24 & III & mujer & 0.15 & 0.19 & 0.32 & 0.71 \\
\hline & & & media 0.18 & media 0.26 & media 0.36 & media 0.76 \\
\hline & \multicolumn{2}{|c|}{ Media global } & 0.17 & 0.24 & 0.33 & 0.65 \\
\hline & \multicolumn{2}{|c|}{ Desviación típica } & 0.11 & 0.15 & 0.19 & 0.28 \\
\hline
\end{tabular}

Tabla 7. Realizaciones individuales de elisión

Según se observa en la tabla, las cifras se ajustan a un patrón en forma de uve, por grupos etarios, para todos los entornos: general (I: 0.22; II: 0.12, III: 0.18), restringido (I: 0.30 ; II: 0.17; III: 0.26), morfemático (I: 0.39; II: 0.25; III: 0.36) y -ado (I: 0.67; II: 0.52; III: 0.76). 
a) Entorno general

En el gráfico 7 se refleja el porcentaje individual de elisión de cada hablante en el entorno general. Los usos individuales, como puede verse, muestran una gran desigualdad en sus valores porcentuales.

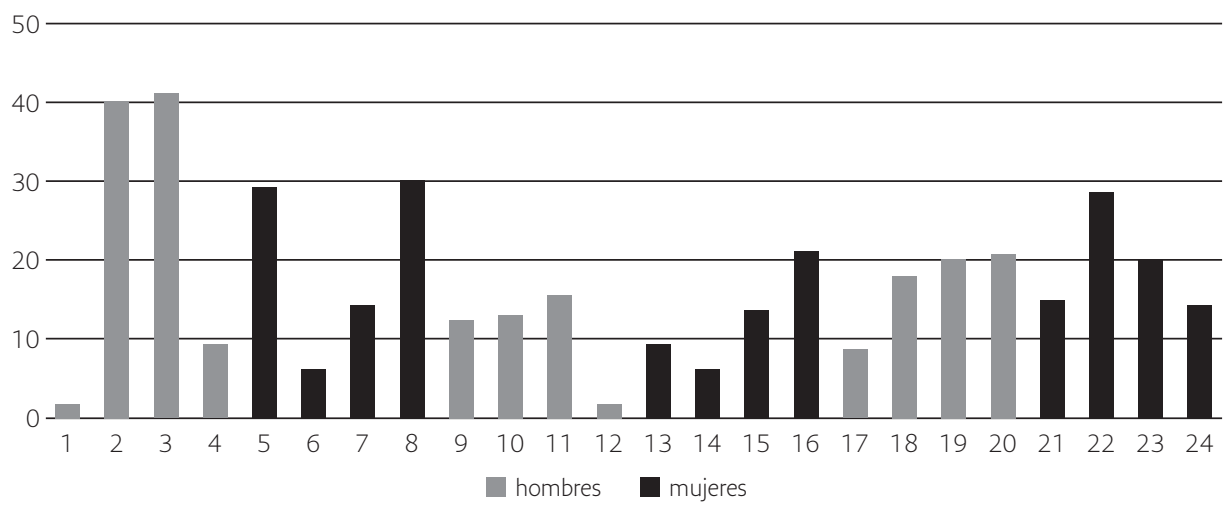

Gráfico 7. Porcentaje individual de la elisión de /d/ (entorno general) ${ }^{8}$

Entre los hombres descubrimos los comportamientos más extremos: los informantes 2 y 3 presentan los valores porcentuales más elevados de elisión, mientras que los informantes 1 y 12 reflejan las cifras más bajas de pérdida. Asimismo podemos comprobar cómo los hablantes (hombres y mujeres) de la segunda generación (informantes núms. 9 al 16) apenas superan el $15 \%$ de elisión, solo el informante 16 se sitúa por encima de ese porcentaje, con un $21.1 \%$. Se confirma pues esa tendencia que frena la elisión por parte de la generación intermedia en contraste con los resultados hallados en jóvenes y mayores.

En el gráfico 8, donde se detalla la diferencia de cada individuo con respecto a la media de la elisión, la franja de valores negativos comprende 14 personas ( 7 hombres y 7 mujeres), mientras que en la franja de valores positivos, que favorecen la elisión, encontramos 10 sujetos (5 hombres y 5 mujeres). Al igual que sucede con los hablantes madrileños, aquí también los porcentajes

8. Los informantes se ordenan como sigue: 1 al 4 (hombres, I generación), 5 al 8 (mujeres, I generación), 9 al 12 (hombres, II generación), 13 al 16 (mujeres, II generación), 17 al 20 (hombres, III generación) y 21 al 24 (mujeres, III generación). 
que se distribuyen por la zona positiva poseen un rango mayor que los que se establecen en la banda negativa. Así pues, los que promueven el cambio innovador presentan un comportamiento menos homogéneo que quienes se resisten a él.

Sirviéndonos del resultado de la desviación típica (0.11), podemos descubrir los hablantes que destacan por fomentar o rechazar la innovación fonética. En el gráfico 8 se puede advertir que un total de cuatro informantes $(2,3$, 5 y 8 ) se posicionan por encima de dicho valor, lo cual indica que son quienes más favorecen la elisión y, por consiguiente, líderes lingüísticos de la innovación. Se trata de un grupo perteneciente a la generación más joven y repartido por igual entre hombres y mujeres. Los informantes 2 y 3 ofrecen las conductas lingüísticas más avanzadas, esto es, muy por encima de la desviación típica.

Por su parte, los hablantes de la zona negativa, que mantienen la dental en la mayoría de sus ocurrencias, se corresponden con los informantes de edad intermedia.

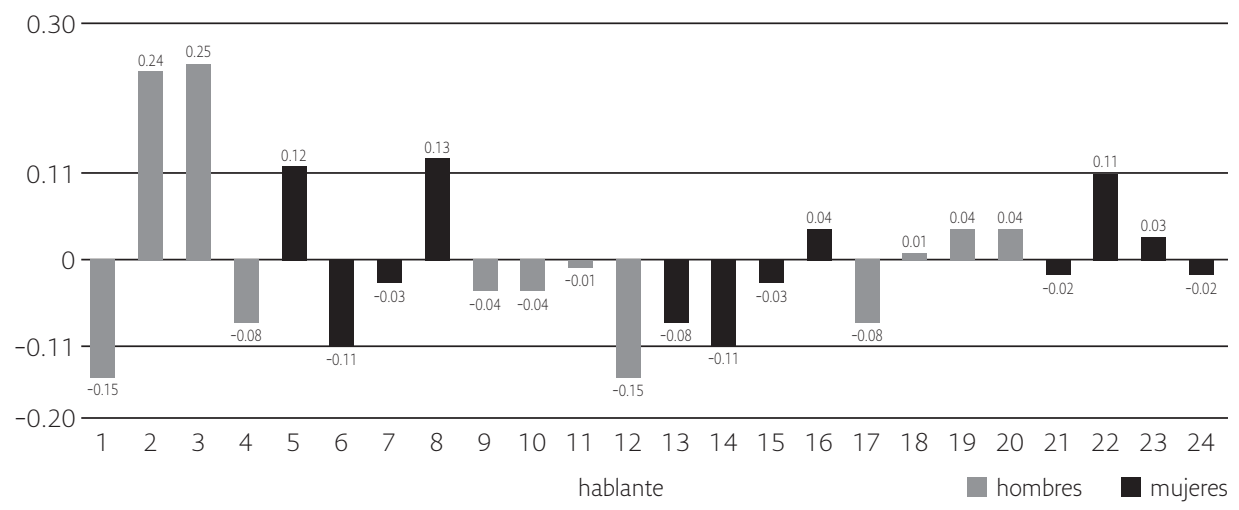

Gráfico 8. Diferencia de cada sujeto respecto a la media de elisión (entorno general)

b) Entorno - ado

En el entorno -ado la elisión alcanza el $69.7 \%$. La pérdida de la dental en este contexto lingüístico, pese a ser rechazada tajantemente en sus primeros testimonios orales por considerarse fenómeno vulgar (Menéndez Pidal $\$ 35$, 4; Navarro Tomás 101-02; Narbona/Cano/Morillo 176), en la actualidad se ha convertido en una solución fonética con una importante aceptación so- 
cial. Se advierte además que los usos individuales manifiestan unos comportamientos lingüísticos muy distintos a los examinados en el entorno general (gráfico 7). En esta ocasión, son muy pocos los sujetos que eliden la dental por debajo del $50 \%$ (informantes 1, 6, 10,12, 14 y 17), con lo que se confirma, por tanto, que el proceso de desgaste de la dental está bastante avanzado. Asimismo, un grupo de cinco personas favorecen la elisión más allá del $90 \%$ (informantes 2, 3, 5, 8 y 16), de los que cuatro pertenecen a los miembros más jóvenes de la muestra, repartiéndose por igual entre hombres y mujeres. En esta generación, llaman la atención los dos casos que se apartan notablemente de la tendencia mayoritaria del grupo (informantes 1 y 6), quienes obtienen el $12.5 \%$ y $20 \%$ de elisión, respectivamente. Por otro lado, constatamos en este gráfico que nuevamente se repite el patrón en forma de uve visto en el contorno fónico general. Si nos fijamos en los tres grupos de edad, comprobaremos que son los sevillanos cultos de la segunda generación quienes menos favorecen la elisión, lo cual contrasta, como ya sabemos, con la tendencia innovadora de los restantes grupos: en la primera generación eliden $5 / 8$, en la segunda $2 / 8$ y en la tercera $7 / 8$. Por sexo, apreciamos escasa diferencia en los resultados. Así, por ejemplo, por encima del $80 \%$ de elisión hallamos plena igualdad entre hombres y mujeres (5 en cada caso).

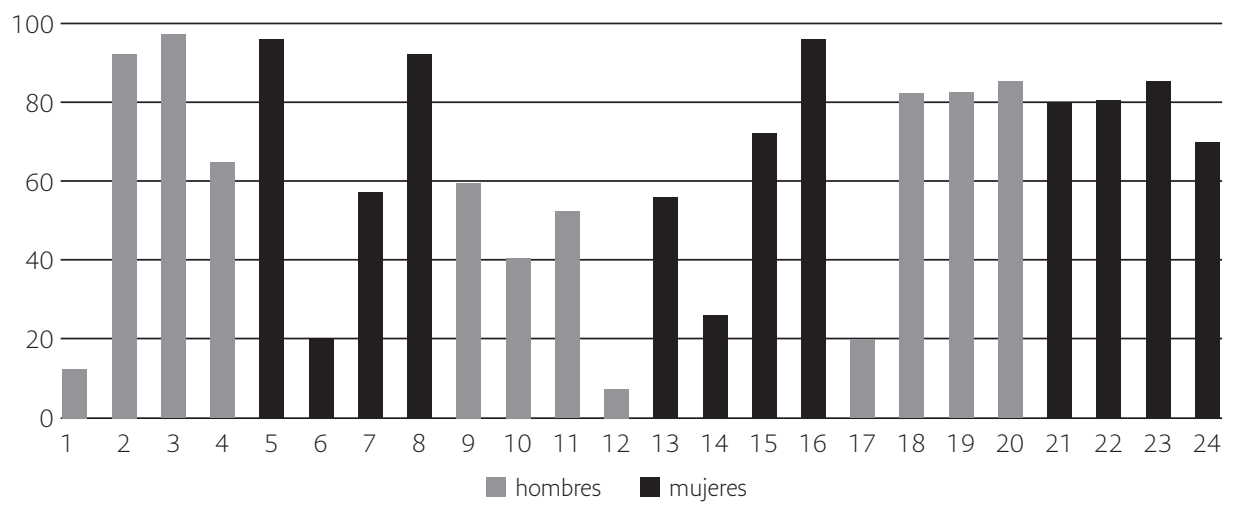

Gráfico 9. Porcentaje individual de la elisión de /d/ (entorno -ado)

En cuanto a la distribución de nuestros informantes teniendo en cuenta la media de elisión (57\%), podemos decir que 14 encuestados eliden más de la media (6 hombres y 8 mujeres) y 10, menos (6 hombres y 4 mujeres). Tam- 
bién, observamos una acusada oscilación entre quienes más eliden la dental $(0.32 \%)$ y los que menos $(0.57 \%)$.

Partiendo de la consideración de la desviación típica, que es del 0.28 , podemos comprobar que quienes lideran el cambio lingüístico son los informantes 3,5 y 16 . Todos ellos muestran una desviación respecto a la media de entre 0.32 y 0.31 puntos porcentuales y son los informantes 3,5 y 16 (un hombre y una mujer de la primera generación y una mujer de la segunda generación, la cual se aparta de la conducta lingüística del resto de sujetos de su misma generación. Frente a este grupo favorecedor del cambio, se encontrarían los hablantes más conservadores (informantes 1, 6, 12, 14 y 17). Debemos destacar, finalmente, que ningún hablante elidió todas las ocurrencias terminadas en -ado, si bien todos en mayor o menor medida practican la elisión. El que más próximo estuvo del $100 \%$ de elisión fue el informante 3 (hombre, primera generación).

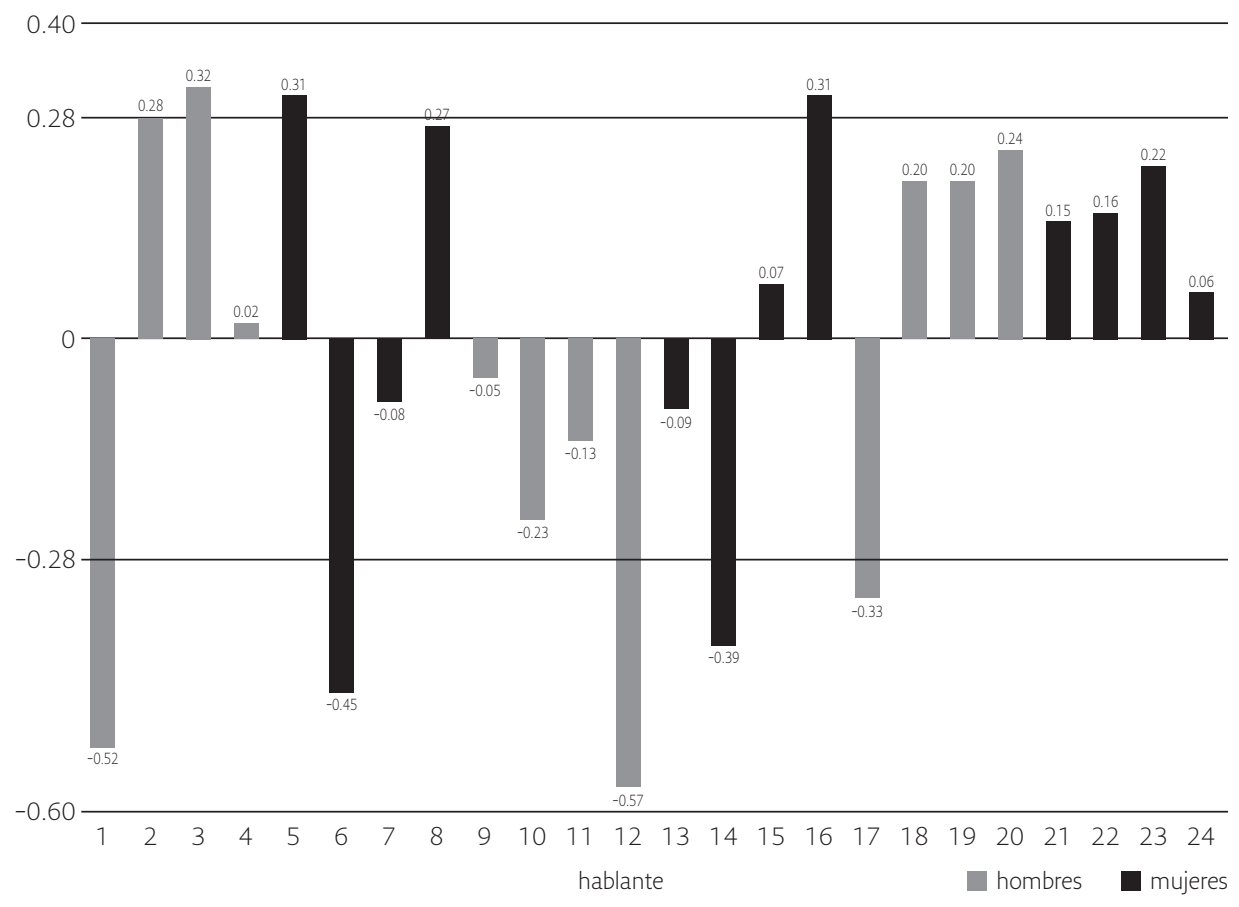

Gráfico 10. Diferencia de cada sujeto respecto a la media de elisión (entorno -ado) 


\section{Análisis multivariante}

Mediante el modelo probabilístico de análisis multivariante, intentamos explicar la interacción conjunta de todos los factores sobre la variable dependiente, así como el peso determinado de cada uno de ellos. En efecto, con el análisis de regresión logística se puede comprobar en qué medida contribuyen solidariamente las variables seleccionadas a explicar la variación observada y determinar la incidencia que tienen las variables independientes sobre la elisión de la $d$ intervocálica cuando ambas se correlacionan (Molina Martos/Paredes García 99).

Asimismo, con el análisis de subida y bajada (binomial up \& down), aparte de obtenerse los pesos probabilísticos, el programa nos selecciona los grupos de factores estadísticamente significativos, descartando los que no lo son, y selecciona la combinación de grupos de factores más adecuada para la investigación.

Para llevar a cabo este aspecto nos hemos ayudado del GoldVarb X, ${ }^{9}$ programa informático desarrollado por Sankoff/Tagiante/Smith, del cual hemos obtenido los resultados que se detallan en la tabla 8.

Una vez hechos los cálculos, el programa elimina la incidencia de 11 de los 20 factores analizados, ya sea por su escasa influencia o porque no son estadísticamente significativos. Las variables independientes eliminadas son las siguientes: lingüísticas (número de sílabas, entorno consonántico de la palabra, entorno consonántico secuencial, categoría gramatical, categoría léxica, funcionalidad, difusión léxica y asimilación al turno de palabra anterior), estilísticas (especialización y fase de interacción) y sociológicas (sexo). El programa también establece las variables significativas en la elisión de la dental (9, en nuestro caso).

En la tabla siguiente se muestran ordenadas de forma decreciente las variables independientes según su rango (elemento de medición del grado de incidencia en la elisión) y se indica el peso probabilístico específico de cada variante dentro del grupo de factores correspondiente.

Según los resultados de la tabla, se observa que son las variables lingüísticas las que presentan una mayor incidencia en la probabilidad de la elisión, seguido por las estilísticas y las sociales.

9. Las variantes que posean valores superiores a 0.500 serán significativas, tienden a favorecer la elisión y, cuanto más se aproximen a 1, mayor peso probabilístico tendrán. Sin embargo, si tienen valores por debajo de 0.500 , la tendencia es la de impedir la elisión y en caso de mantenerse en 0.500 o bien muy próximo a este, ni potencian ni retienen el fenómeno. 
JIMÉNEZ FERNÁNDEZ. VARIACIÓN FONOLÓGICA DE LA /d/ INTERVOCÁLICA EN SEVILLA

\begin{tabular}{|c|c|c|}
\hline RANGO Y VARIABLES INDEPENDIENTES & VARIANTES & $\begin{array}{c}\text { PESO } \\
\text { PROBABILIISTICO }\end{array}$ \\
\hline \multirow{5}{*}{ 1. Entorno vocálico posterior (rango 0.82) } & {$[1]$} & 0.900 \\
\hline & [o] & 0.781 \\
\hline & [ó] & 0.553 \\
\hline & [a] & 0.135 \\
\hline & {$[e]$} & 0.074 \\
\hline \multirow{5}{*}{ 2. Entorno vocálico previo (rango 0.69) } & [á] & 0.792 \\
\hline & [a] & 0.650 \\
\hline & [i] & 0.608 \\
\hline & [ó] & 0.191 \\
\hline & {$[1]$} & 0.102 \\
\hline \multirow{3}{*}{ 3. Posición del acento (rango 0.65) } & Precede inmediatamente & 0.695 \\
\hline & Sigue mediatamente & 0.520 \\
\hline & Sílaba tónica & 0.043 \\
\hline \multirow{3}{*}{ 4. Tenor-edad (rango 0.58) } & $\mathrm{DE}$ & 0.665 \\
\hline & Edad igual o aproximada & 0.447 \\
\hline & $\mathrm{I} \mathrm{E}$ & 0.080 \\
\hline \multirow{4}{*}{ 5. Homofonía (rango 0.54) } & Otros casos & 0.770 \\
\hline & Adjetivo-nombre/participio & 0.509 \\
\hline & Ausencia & 0.436 \\
\hline & Adjetivo y nombre & 0.226 \\
\hline \multirow{2}{*}{ 6. Estructura acentual (rango 0.44) } & Paroxítona & 0.590 \\
\hline & Proparoxítona & 0.147 \\
\hline \multirow{2}{*}{ 7. Límite morfemático (rango 0.43) } & Morfema & 0.750 \\
\hline & Lexema & 0.312 \\
\hline \multirow{3}{*}{ 8. Edad (rango 0.35) } & Primera generación & 0.732 \\
\hline & Segunda generación & 0.380 \\
\hline & Tercera generación & 0.373 \\
\hline \multirow{3}{*}{ 9. Tenor-proximidad (rango 0.17) } & Insider & 0.529 \\
\hline & Outsider & 0.398 \\
\hline & Entrevista & 0.352 \\
\hline
\end{tabular}

Log likelihood $=-562.177 ;$ Significance $=0.044$

Tabla 8. Jerarquía de rango y variables (entorno general) 


\section{CONCLUSIONES}

1. En el entorno general, la elisión de la dental se produce en el $18 \%$ de los casos. Con respecto a otras comunidades de habla, los hablantes cultos de Sevilla presentan unos índices porcentuales de elisión por encima de Valencia (10.7\%) y Madrid (14.2\%), cuya tendencia general es a la conservación del sonido dental, algo superior al de Las Palmas $(16.1 \%)$ y por debajo de los resultados alcanzados en otras poblaciones andaluzas, como Granada (23.1\%) y Málaga (24 \%). En consecuencia, constatamos para Sevilla un proceso de elisión más avanzado que el existente en las hablas castellanas septentrionales (hipótesis 1) y, por otro lado, menos acusado con respecto al de otras ciudades andaluzas (Villena/Moya).

2. Las variables lingüísticas, tal como adelantábamos en la hipótesis 2, son más determinantes en la variación de este fenómeno que los factores externos (situacionales o sociales). Las variables internas más influyentes en la pérdida o el mantenimiento de la dental, enunciadas de mayor a menor incidencia, son el contorno vocálico (vocales previas o posteriores), la categoría gramatical, el límite morfemático, el acento, la homofonía, la difusión léxica, así como la estructura acentual. Todas ellas presentan unas correlaciones entre variables de carácter moderado frente al resto de factores internos y externos, que manifiestan una débil asociación. Según se preveía en la hipótesis 3, el entorno vocálico previo y posterior es el factor que más peso ha mostrado en la variación de /d/. Igualmente, la pérdida de la dental depende mucho de que esta pertenezca al morfema de la palabra (sufijo morfemático verbal de participio, sustantivos y adjetivos derivados). En cambio, cuando se encuentra en la base lexemática su desaparición queda altamente frenada. Ciertamente, el lexema se ve afectado por la desaparición de /d/ en los casos de todo, casi con los mismos porcentajes ya funcionaran como pronombres o como modificadores, y nada (hipótesis 4). También se comprueba la hipótesis 5, dado que son los participios verbales y adjetivos derivados las categorías gramaticales que más determinan la variante elidida, sobre todo, en la terminaciones en -ado.

3. En cuanto a los factores socioestilísticos (hipótesis 6), hombres y mujeres ofrecen unos datos muy parecidos, nada relevantes, lo cual queda corroborado con los valores no significativos aportados por la prueba estadística $j i-$ cuadrado. Conforme a la estratificación por grupos de edad, los jóvenes lideran el avance de la innovación del cambio fonético. Tal como ha sido observado en otras investigaciones (Molina Martos/Paredes García 107; Villena/Díaz/ 
Ávila/Lasarte 337), la elisión en esta variable adopta un patrón gráfico en forma de uve, esto es, tendencia frenada por los individuos de la segunda generación y avanzada en las dos restantes: con mayor vitalidad en jóvenes que en mayores. Este mismo modelo se repite si interaccionamos el sexo con la edad: conservación en la generación intermedia frente a innovación en las otras dos. Entre las variables diafásicas, solo la fase de interacción se presenta sin significación estadística; no obstante, se aprecian menos ocurrencias elididas en el comienzo de la entrevista que en las fases intermedia y final. Por su parte, la solidaridad y la proximidad condicionan la elisión, pues esta posee mayor peso cuando los participantes cuentan con una edad muy cercana y una estrecha relación familiar o personal. Podemos decir, en consecuencia, que partir de una situación informal contribuye de modo muy positivo al refuerzo del fenómeno de elisión.

4. El entorno propicio - ado se convierte en el contexto donde la innovación fónica se muestra más extrema, con casi un 70 \% (hipótesis 7). De los 363 casos de elisión, el $50.9 \%$ corresponde a participios verbales y el $28.6 \%$ a adjetivos derivados participiales (ambas categorías alcanzan casi el $80 \%$ ). Aquí también, analizando conjuntamente las variables de hablante (sexo y edad), se comprueba que los porcentajes de la variante elidida se distribuyen en forma de uve, si bien, a diferencia del comportamiento examinado en los demás entornos lingüísticos, quienes lideran el avance de la elisión son los mayores (74.62 \%) en vez de los más jóvenes (66.67 \%).

5. El comportamiento individual en el entorno general se manifiesta con porcentajes muy desiguales. Los índices más elevados corresponden a la primera generación, donde dos hablantes masculinos alcanzan los resultados extremos. Todos los sujetos favorecen la elisión, si bien no todos en la misma medida. Comprobamos también cómo la segunda generación se resiste al cambio innovador (en la mayoría la elisión no supera el 15 \%), de modo que se ajusta al patrón en uve, ya constatado en otros estudios citados. Con respecto al entorno - ado, el más propicio para la elisión, la potencia con mucha fuerza: son muy pocos los individuos que omiten el sonido dental por debajo del $50 \%$. Seis informantes (5 de ellos jóvenes) eliden más allá del 90 \% y el resto lo hace por encima de la media. En este contexto fónico vuelve a aparecer el modelo de patrón ya descrito para el entorno general, pues son los jóvenes y los mayores los que propician con fuerza la desaparición de la aproximante.

6. En cuanto al análisis multivariante aplicado, podemos decir que los grupos de factores más significativos en el peso probabilístico de la elisión son 
los siguientes: entorno vocálico posterior, entorno vocálico previo, posición del acento, tenor-edad, homofonía, estructura acentual, límite morfemático, edad y tenor-proximidad.

7. El fenómeno de variación que nos ocupa se halla condicionado por razones morfológicas y léxicas (Moya/García Wiedemann 119). En efecto, el gran desgaste de la /d/ intervocálica afecta fundamentalmente a los participios (con función verbal o adjetiva) y a la forma todo (ya actúe como núcleo o modificador). Conjuntamente, suman 367 ocurrencias con variante elidida (367/457). Desde el punto de vista léxico, se corrobora la agrupación de casos de elisión en los participios y adjetivos frente a los ejemplos de retención de verbos y adverbios y, en menor grado, nombres. A esto hemos de añadir las formas léxicas de uso muy frecuente como todo y nada. Coincidimos con Moya/García Wiedemann (120) en que la pérdida de /d/ intervocálica es un proceso de cambio lingüístico restringido a los participios pasivos, adjetivos deverbales y determinadas unidades léxicas.

\section{OBRAS CITADAS}

Alba, Orlando. "Elisión de /d/ intervocálica en el español dominicano". Estudios de linguiistica hispánica: homenaje a María Vaquero. San Juan de Puerto Rico: Universidad, 1999. 3-21.

Bustos Tovar, Eugenio de. Estudios de asimilación y disimilación en el ibero-románico. Anejos de la RFE 70. Madrid: CSIC, 1960.

Cedergren, Henrieta. "La elisión de la /d/: un ensayo de comparación dialectal". Boletín de la Academia Puertorriqueña de la Lengua Española 7 (1979): 19-29.

D’Introno, Francesco, y Juan Manuel Sosa. "Elisión de la /d/ en el español de Caracas: aspectos sociolingüísticos e implicaciones teóricas". Anuario de la Escuela de Letras UCV (1979): 33-61.

Gómez Molina, José Ramón. "Estudio sociolingüístico del español de Granada, Las Palmas, Lleida, Madrid-Alcalá, Málaga y Valencia”. Lingiuística 17 (2005): 164-73.

Gómez Molina, José Ramón. "Interacción de factores internos y externos en la pronunciación de la /d/ intervocálica”. El español de Valencia: estudio sociolinguiistico. Ed. José Ramón Gómez Molina. Berna: Peter Lang, 2013. 31-68. Gómez Molina, José Ramón, y María Begoña Gómez Devís. "Mantenimiento y elisión de la /d/ intervocálica en el español de Valencia". Verba 37 (2010): 89-122. 
Jiménez Fernández, Rafael. "Sobre el mantenimiento y la pérdida de la /d/ intervocálica en el habla de Sevilla (sociolecto bajo)". Sociolingiuística andaluza 17. La variación en el español actual: estudios dedicados al profesor Pedro Carbonero. Eds. Marta León-Castro Gómez y Adamantía Zerva. Sevilla: Universidad de Sevilla, 2015. 193-209.

Jiménez Fernández, Rafael. "Elisión de la /d/ intervocálica en hablantes de nivel sociocultural bajo de Sevilla”. Lengua y Habla 23 (2019): 258-85.

Lapesa, Rafael. Historia de la lengua española. 9. a ed. Madrid: Gredos, 1981.

Malaver, Irania, y Lorena Perdomo. "La elisión de /d/ en posición intervocálica en la comunidad caraqueña". Boletín de Filología 51.2 (2016): 147-79. Menéndez Pidal, Ramón. Manual de gramática bistórica. 10. ${ }^{a}$ ed. Madrid: Espasa Calpe, 1958.

Molina Martos, Isabel. "Geografía y estratificación social de un cambio fonético: la -d- en español peninsular". Verba 28 (2001): 81-99.

Molina Martos, Isabel. "Innovación y difusión del cambio lingüístico en Madrid". Revista de Filología Española 86.1 (2006): 127-49.

Molina Martos, Isabel. "La tensión del cambio lingüístico: a propósito de la elisión de la /d/ intervocálica". El español del siglo XXI (Actas de las XIV fornadas sobre la lengua española y su enseñanza). Ed. Esteban Montoro del Arco. Granada: EUG, 2009. 211-20.

Molina Martos, Isabel, y Florentino Paredes García. "Sociolingüística de la elisión de la dental /d/ en Madrid (Distrito de Salamanca)". Cuadernos de Linguiistica 2 (2014): 55-114.

Moreno Fernández, Francisco. "Cambios vivos en el plano fónico del español: variación dialectal y sociolingüística". Historia de la lengua española. Coord. Rafael Cano. 2. ed. Barcelona: Ariel, 2004. 973-1010.

Moya, Juan Antonio. "Perdido. Resultados de la terminación -ido en el corpus PRESEEA-Granada". RFULL 30 (2012): 111-30.

Moya, Juan Antonio, y Emilio García Wiedemann. "La elisión de /d/ intervocálica en el español culto de Granada: factores lingüísticos". Pragmalingüística 17 (2009): 92-123.

Narbona, Antonio, Rafael Cano y Ramón Morillo. El español hablado en Andalucía. Barcelona: Ariel, 1998.

Navarro Correa, Manuel. "La variación del segmento /d/ en Puerto Cabello". Boletín de la Academia Puertorriqueña de la Lengua Española 9 (1983): 65-72. Navarro Tomás, Tomás. Manual de pronunciación española. 21. ${ }^{a}$ ed. Madrid: CSIC, 1981. 
Salvador, Gregorio. Estudios dialectológicos. Madrid: Paraninfo, 1986.

Samper, José Antonio. Estudio sociolingiuístico del español de Las Palmas de Gran Canaria. Las Palmas de Gran Canaria: La Caja de Canarias, 1990.

Samper, José Antonio. "El debilitamiento de la -/d/- en la norma culta de Las Palmas de Gran Canaria". Actas del X Congreso Internacional de la Asociación de Lingüística y Filología de la América Latina. México: UNAM, 1996. 792-96.

Samper, José Antonio. "Elisión de /d/ en los niveles de estudios primario y universitario de Las Palmas de Gran Canaria. Comparación con otras comunidades de habla". Sintaxis y análisis del discurso hablado en español: homenaje a Antonio Narbona. Vol. 1. Eds. José Joaquín Bustos Tovar y otros. Sevilla: Universidad de Sevilla, 2011. 409-24.

Samper, José Antonio, y Ana María Pérez. "Variación fonética y cambio en dos modalidades del español de Canarias". Lengua, variación y contexto: estudios dedicados a Humberto López Morales. Vol. 2. Eds. Francisco Moreno Fernández y otros. Madrid: Arco/Libros, 2003. 805-21.

Samper, José Antonio, y Clara Eugenia Hernández. "Un estudio de variación fonética en el marco del PRESEEA: realizaciones de /d/ entre los hablantes de nivel universitario de Las Palmas de Gran Canaria". Lingüística Española Actual 32 (2010): 5-34.

Sankoff, David, Sali A. Tagliamonte y Eric Smith. GoldVarb X: A Variable Rule Application for Macintosh and Windows. Toronto: Universidad de Toronto, 2005. 28 de noviembre de 2017. <www.individual.utoronto.ca/tagliamonte/goldvarb.html>.

Villena, Juan Andrés. "Restricciones de concurrencia entre las consonantes obstruyentes fricativas en los dialectos innovadores del español: datos de la variación fonológica en el español de Andalucía”. Lengua, variación y contexto: estudios dedicados a Humberto López Morales. Eds. Francisco Moreno Fernández y otros. Madrid: Arco/Libros, 2003. 907-22.

Villena, Juan Andrés. "La formación del español común en Andalucía: un caso de escisión prestigiosa". Fonología instrumental: patrones fónicos y variación. Eds. Esther Herrera y Pedro Martín Butragueño. México: El Colegio de México, 2008. 211-53.

Villena, Juan Andrés, y Juan Antonio Moya. "Análisis comparativo de un cambio fonológico erosivo: variación de /d/ intervocálica en dos comunidades de habla (Granada y Málaga)”. Boletín de Filología 51.2 (2016): 281-321.

Villena, Juan Andrés, Francisco Díaz, Antonio Ávila y María de la Cruz Lasarte. "Interacción de factores fonéticos y gramaticales en la variación fo- 
JIMÉNEZ FERNÁNDEZ. VARIACIÓN FONOLÓGICA DE LA /d/ INTERVOCÁLICA EN SEVILLA

nológica: la elisión de /d/ intervocálica en la variedad de los hablantes universitarios en la ciudad de Málaga". Variación lingüística y contacto de lenguas en el mundo hispánico: in memoriam Manuel Alvar. Eds. Yolanda Congosto y Elena Méndez. Madrid: Iberoamericana/Frankfurt: Vervuert, 2011. 311-59.

Zamora Vicente, Alonso. Dialectología española. Madrid: Gredos, 1967. 